\title{
Electroencephalographic Intercentral Interaction as a Reflection of Normal and Pathological Human Brain Activity
}

\author{
Galina N. Boldyreva, Ludmila A. Zhavoronkova, Elena V. Sharova, \\ and Irina S. Dobronravova \\ Institute of Higher Nervous Activity and Neurophysiology of the Russian Academy of Sciences, Moscow
}

\begin{abstract}
The authors summarized EEG findings and defined the nature of the intercentral EEG relationships in different functional states in healthy subjects and patients with organic cerebral pathology, based on a coherence analysis. Similar EEG characteristics in healthy individuals were identified: an anterior-posterior gradient of average coherence levels, the type of cortical-subcortical relationships in anterior cerebral structures. Right- and left-handed individuals showed frequent and regional differences in EEG coherence, which mainly reflected specificity of intracortical relationships. Development and regression of pathology in right-and left-handed individuals with organic brain lesions were thought to be caused by these differences. Lesions of regulatory structures (diencephalic, brain stem and limbic structures) provoked a more diffused kind of changes of intercentral relationships, in contrast to cortical pathology. These changes tended to reciprocate. The dynamic nature of intercentral relationships and their interhemispheric differences was revealed when changing functional states of the brain (increase and decrease of functional level) in healthy individuals and patients with organic cerebral pathology in the process of conscious and psychic activity restoration. Changing activity predominance of certain regulatory structures was considered one of the most important factors determining the dynamic nature of EEG coherence.

Keywords: EEG, coherence analysis, interhemispheric asymmetry, brain pathology
\end{abstract}

\begin{abstract}
Los autores resumen los resultados de las investigaciones de las relaciones intercentrales de EEG de personas sanas en distintos estados funcionales y de enfermos con lesiones orgánicas del SNC, mediante análisis de coherencia. Se revelan características semejantes de la estructura de relaciones de EEG de personas sanas: la gradiente anterior-posterior de niveles medios de coherencia, el carácter de la interacción cortical-subcortical de las secciones anteriores de los hemisferios. A su vez, se detectan diferencias de frecuencia y regionales en la coherencia de EEG en diestros y zurdos, que reflejan mayoritariamente la especificidad de la interacción intracortical. Se cree que estas diferencias causan la especificidad del desarrollo y la regresión de los estados patológicos de diestros y zurdos en lesiones cerebrales orgánicas. Se señala que en las lesiones de formaciones reguladoras (diencefálicas, troncales, límbicas) Provocan unos cambios de las relaciones intercentrales más difusos que en casos de patología cortical. Estos cambios tienden a la reciprocidad. Se revela el carácter dinámico de las relaciones intercentrales y sus diferencias interhemisféricas en los cambios de los estados funcionales del cerebro (incremento, disminución del nivel de funcionamiento) en personas sanas así como en la recuperación de la conciencia y la actividad psíquica en enfermos con patología cerebral orgánica. Uno de los factores que determina el carácter dinámico del cambio de la coherencia del EEG es el cambio del predominio de la actividad de ciertas estructuras reguladoras.

Palabras clave: EEG, análisis de coherencia, asimetría interhemisférica, patología cerebral
\end{abstract}

Supported by Russian Foundation of Fundamental Research N ${ }^{\circ}$ 04-04-48428a and Russian Foundation of Humanitarian Scientist Research No 05-06-06543a.

Correspondence concerning this article should be sent to Galina N. Boldyreva, Moscow, 117475, ul. Butlerova. 5a. E-mail: GBoldyreva@nsi.ru 
One of the methods used to study brain activity mechanisms is research of the properties of spatial-temporal organization of brain electrical activity (electroencephalogram or EEG) in various functional conditions. Of specific importance is the study of EEG reorganization in organic brain damage with various degrees of cerebral functioning disturbance. For several years, the use of EEG in neurosurgery has been centered on the revelation of brain lesions. Recently, in the light of the rapid development of neuroradiology (computer tomography, magnetic resonance tomography), the use of EEG as a tool of topical diagnosis has diminished in relevance. Of greater relevance is the clarification of the extent of damage to integral brain activity and the level of decompensation.

\section{Participants and Methods}

Research in the past years using various mathematic methods of EEG analysis has shown that the most adequate approach to the solution of contemporary problems of clinical electroencephalography is the analysis of intercentral interactions on the basis of EEG coherence calculation (Boldyreva, Sharova, Zhavoronkova, \& Dobrokhotova, 1992; Boldyreva, Zhavoronkova, Sharova, \& Dobronravova, 2003; Rusinov, Grindel, Boldyreva, \& Vakar, 1987; Sharova, Borodkin, Gognitidze, Lukianov, \& Muhanov, 1992; Sharova, Manelis, Kulikov, \& Barkalaia, 1995; Sharova, Obraztsova, Zaitsev, Kulikov, \& Urakov, 2001; Zhavoronkova, 2006). This standing is in accordance with the classical conception of Rusinov (1969) and Livanov (1972) on the significance of spatial synchronization of biopotentials in the maintenance of integral brain activity. The promise of such an approach is further supported by results of the comparison of EEG coherence and cerebral metabolic processes (Newton et al., 1993) and the anatomic organization of the brain (Thatcher, 1994).

The functional significance of EEG coherence characteristics has been noted in several studies (Farber, 1990; Rappelsberger \& Petshe, 1988; Schack \& Krause, 1995; Tucker, Roth, \& Bair, 1986). However, as of 1975 , the most systematic research of EEG coherence spectrums in healthy subjects and in patients with focal brain damage has been carried out in the N.N. Burdenko Institute of Neurosurgery of the Russian Academy of Medical Sciences. This research was carried out in close scientific alliance with the Institute of Higher Nervous Activity and Neurophysiology of the Russian Academy of Sciences.

The present study shows the principal status of the neurophysiological approach to the study of the mechanisms of integral brain activity, based on the summarization of results of the study of spatial-temporal EEG organization in healthy participants $(N=50)$ and patients with tumor $(N$ $=300)$ and traumatic $(N>400)$ cerebral lesions.
Results

\section{Study of Healthy Participants}

In the study of the EEG structure in healthy subjects, special emphasis was made on the revelation of the properties of the organization of the electrical process in the left and right hemispheres and the nature of their interaction. Literature reviews on EEG hemispheric specificity show that, on the whole, studies have focused on research of reactions to afferent stimulation or of performance of psychological tasks. Furthermore, these studies have been carried out primarily on right-handed subjects (Barchas \& Perlaki, 1986; Beaumont, Mayes, \& Rugg, 1978). The importance of taking functional asymmetry into account in the research of EEG hemisphere specificity is confirmed by clinical data of the differences in psychoneurological symptoms of focal brain damage in left- and right-handed subjects (Dobrokhotova \& Bragina, 1977). The present study presents the analysis of spontaneous and reactive EEG in 20 healthy subjects, taking into account the profile of sensory and motor asymmetry (Bragina \& Dobrokhotova, 1981), and, on the basis of testing the results of the functions of the extremities, sight and hearing, it allows for the accurate determination of the extent of dominance-subdominance of the brain hemispheres. In the group of right-handed subjects of this study $(N=10)$, the following mean values of the asymmetry coefficient were obtained: coefficient for right hand, $\mathrm{Crh}=72 \pm 12 \%$; coefficient for right ear: Crear $=14.9 \pm 2.5 \%$; coefficient for right leg: $\mathrm{Crl}=80 \pm 15 \%$; and coefficient for right eye: Creye $=77 \pm 11$. Positive values indicate dominance of right asymmetry for all the analyzed sensory and motor organs. The left-handed group $(N=10)$ presented the following mean values: $\mathrm{Crh}=-42 \pm 5 \%$; Crear $=-13 \pm 3.5 \% ; \mathrm{Crl}=$ $-35 \pm 10 \%$; and Creye $=-21 \pm 11 \%$. Negative values correspond to the predominance of left asymmetry.

Analysis of intercentral interactions of brain electrical processes in healthy subjects in a state of relative rest revealed that the average levels of coherence (Rusinov et al., 1987) of symmetrical hemisphere regions independent of EEG type (alpha activity characteristics) and individual asymmetry profiles are characterized by a significant similarity and the presence of an anterior-posterior falling gradient of biopotential association. Oscillation of the potentials of the frontal regions was maximally coherent, reflecting maximum synchronization of their functional activity. Minimum synchronization was noted at temporal electrode sites as a result of greater functional hemispheric specialization and, in part, the maximum distance between these regions.

Furthermore, the specifics of hemispheric interrelations, to a great extent, are determined by the individual characteristics of functional asymmetry. In right-handed subjects in a state of rest, average levels of coherence are, 
on the whole, of greater value in the left hemisphere. In left-handed subjects, the opposite is seen, with greater coherence in the right hemisphere (Zhavoronkova, 2006). Characterization of the features of difference in EEG coherence is achieved by annotation of the coefficient of interhemispheric asymmetry, calculated according to indices of mean levels of EEG coherence. This coefficient can be calculated as a sum of all analyzed electrode pairs (integral $\mathrm{Ca}$ ) or separately for each cortex region (regional $\mathrm{Ca}$ ). Maximum hemispheric coherence differences in both groups of subjects were noted at lateral electrode pairs (frontotemporal). Median pairs (central-frontal), however, showed maximum values in the right hemisphere in both right- and left-handed subjects.

The calculation of the coherence asymmetry coefficient for separate EEG spectral bands allows for the clarification of the contribution of various EEG frequency components in the formation of the hemisphere difference.

It turns out that maximum asymmetry in the lateral electrode pairs in all subjects is within the alpha, and partially beta, diapason. Asymmetry at median electrode sites is formed primarily by theta-rhythm.

The observed regional and frequency characteristics of biopotential inter-hemispheric coherence asymmetry of healthy subjects has been examined with reference to data on the genesis of separate EEG rhythm components (Gevins \& Remond, 1987; Lopez da Silva, 1991) and has lead to the suggestion that EEG hemisphere differences in rightand left-handed subjects are reflected predominantly in the organization of cortical connections.

An important characteristic of brain electrical activity is the measurement of the stability of EEG intercentral interactions. The study of the dynamics of EEG coherence with varying temporal intervals (days, months, years) in healthy subjects revealed that, with significant temporal stability of the coherence of symmetrical hemisphere zones, there is considerable variability in interhemispheric connections. Furthermore, right-handed subjects show greater stability of electrical processes in the left-dominant hemisphere in comparison to the right-subdominant hemisphere (Boldyreva, 1994). The fact that this feature is predominant specifically in the dominant hemisphere is in accordance with the concept of Shepoval'nikov and Citseroshin (1999) of the role of the existence of stable intersystemic interconnections of nerve elements with the ability to maintain dynamic structure.

One of the approaches to the study of the neurophysiological mechanisms of integral brain activity is the analysis of neurodynamic reorganization as a result of changes in functional state and afferent stimulation. The analysis of changes in intercentral interactions in states of decreased vigilance (transition to somnolence) revealed the evening out of hemispheric differences in brain biopotential organization (Boldyreva \& Zhavoronkova, 1989; Zhavoronkova, Boldyreva, \& Dobrokhotova, 1988;
Zhavoronkova \& Trofimova, 1997, 1998). Figure 1 displays the dynamics of integral coefficient of coherence asymmetry (Ca) in changing levels of vigilance in groups of right- and left-handed individuals. On a background state of vigilance (A), in right-handed subjects, $\mathrm{Ca}$ had positive values due to an excess of coherence in most electrode pairs in the left hemisphere; in left-handed subjects, the values were negative due to greater values of coherence in the right hemisphere. In the transition to somnolence (B), Ca decreased, approaching zero values in both groups, reflecting the evening out on interhemispheric asymmetry. In subsequent deepening of sleep (C), Ca became negative in both left- and right-handed subjects, reflecting greater values of coherence in the right hemisphere. On wakening (D), changes in $\mathrm{Ca}$ were characterized by a tendency towards the initial values of the state of vigilance.

Analysis of changes in coherence in separate EEG spectral bands in transition to somnolence states showed that the evening out of inter-hemisphere asymmetry occurred primarily as a result of a decrease in the predominance in the background of the combination of alpha- and beta-bands in the dominant hemisphere. In right-handed subjects, interhemispheric coherence in the transition to somnolence was characterized by reciprocal changes in quick (alpha and beta) and slow (delta and theta) EEG components; in lefthanded individuals, the changes in all rhythm diapasons were synphasic. The data presented herein underline the importance of the consideration of the dynamics of separate EEG rhythm bands in the assessment of neurodynamic shifts.

The study of the dynamics of intercentral interactions with afferent stimulation showed that reactive shifts in subjects with various asymmetry profiles were multiform. Right-handed subjects (Figure $2 \mathrm{~A}$, a), when moving the

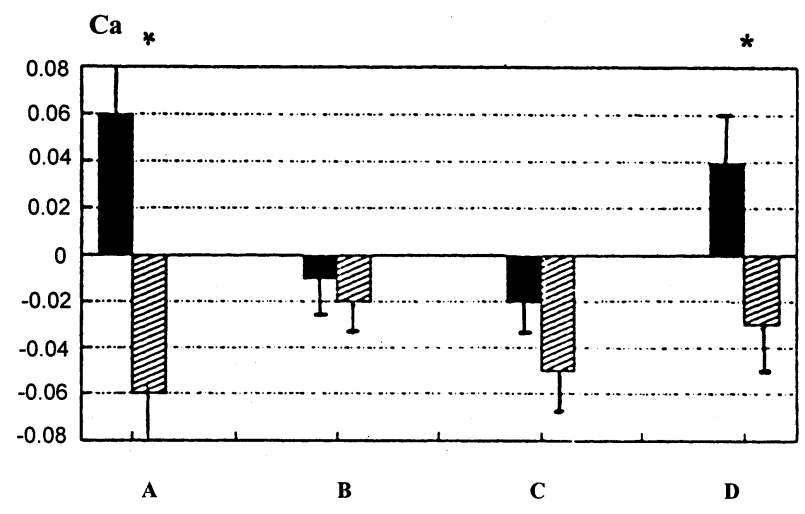

Figure 1. Dynamics of integral CA in changes of vigilance level in right- and left-handed subjects.

Black columns = right-handed subjects; cross-hatch = left-handed subjects.

$\mathrm{X}$-axis = various states: $\mathrm{A}=$ vigilance, $\mathrm{B}=$ first sleep stage, $\mathrm{C}=$ second sleep stage, $\mathrm{D}=$ wakening.

$\mathrm{Y}$-axis $=\mathrm{Ca}$ value

*difference significant at $p<.01$. 
leading (right) hand, showed an increase in EEG coherence in the left hemisphere and a decrease of the same in the right hemisphere. In left-handed subjects under the same conditions, an increase in coherence in both hemispheres was more typical, and more pronounced in the right hemisphere. Maximum changes in EEG coherence with motor exertion were noted in the central-temporal regions of the hemispheres. Analysis of the reactivity of separate biopotential spectral bands of these regions in right-handed subjects revealed the reciprocal nature of the changes in alpha and theta2 spectral bands coherence in the left hemisphere (Figure 2A, b). In left-handed subjects, the coherence of practically all frequency bands with motor performance altered in a synphasic manner (Figure $2 \mathrm{~B}, \mathrm{~b}$ ).

Thus, the data shows that, in right-handed subjects, there is a more complex and differentiated nature of interhemispheric interaction that reflects the reciprocal nature of the involvement of various brain structures in the changes of functional state in comparison to that of left-handed subjects (Zhavoronkova, 2006).

\section{Study of Patients with Brain Lesions}

There is no doubt that the study of neurodynamic reorganization is a promising approach to research into neurophysiological mechanisms of systemic organization in focal forms of cerebral damage. The effectiveness of such an approach is determined by the possibility of precise anatomic verification of the zone of primary damage by computerized and magnetic resonance tomography (CT, MRT), as well as detailed comparison of EEG data with the results of comprehensive clinical investigation including neuropsychological testing.

On the basis of EEG investigation, a majority of patients with brain tumor of varying localization, it was determined that the most complex pattern of EEG reorganization was noted with the involvement of structures of regulatory function of the maintenance of integrative brain activity in the pathological process. Such structures include, first and foremost, diencephalic, limbic, and brain stem areas. It is specifically these structures that are largely responsible for
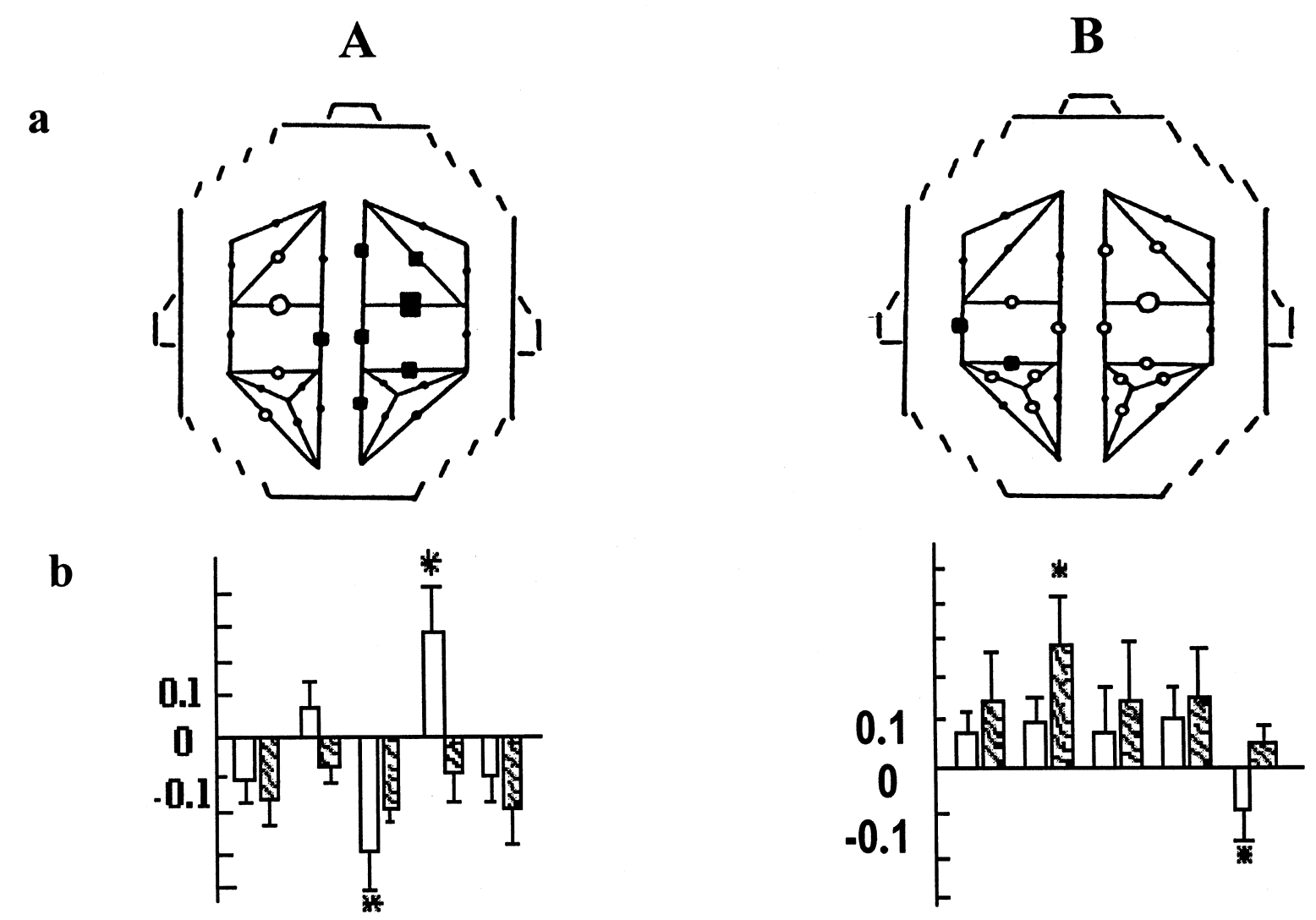

Figure 2. Properties of EEG coherence reactivity in right-handed (A) and left-handed (B) subject during the execution of movements in the leading hand.

$\mathrm{a}=$ regional features of changes in coherence: light circles = increasing EEG coherence in comparison with background; dark squares = decreasing EEG coherence in comparison with background: the dimension of the circles reflects the extent of significant changes.

$\mathrm{b}=$ changes in separated EEG spectral bands in central-temporal cortical regions: positive values = increase in coherence; negative values $=$ decrease in coherence; empty columns $=$ left hemisphere; cross-hatched $=$ right hemisphere,

*changes significant at $p<.01$. 
the maintenance of the level of vigilance and consciousness, emotional background of behavior, integration of complex behavioral and other systemic central nervous system (CNS) reactions. The examination of several variants of the involvement of regulatory structures in the pathologic process revealed specific features of the changes in spatial-temporal EEG organization (Boldyreva, 2000; Boldyreva et al., 1992, 2003; Sharova et al., 1992, 1995; Zhavoronkova, 2006). It was revealed that the disturbance of intercentral interaction is expressed more diffusely in these cases than in cases of cortical damage. This fact is determined by the intimate anatomic and functional connections of regulatory structures with many cerebral regions and reflects the systemic nature of the formation of adaptive neurodynamic reorganization. At the same time, on the background of the diffuse nature of EEG changes, we were able to reveal the specifics of the involvement of diencephalic, stem, and limbic structures in the organization of intercentral interactions of cortical biopotentials. The most prominent influence of diencephalic structures on the formation of EEG organization in the right hemisphere and of stem structures on the left hemisphere was established. This property is in accordance with clinical data, indicating the non-identical nature of interactions of the right and left hemispheres with diencephalic and stem structures (Dobrokhotova \& Bragina, 1977). The pattern of changes in intercentral interactions with damage to limbic structures displays features similar to those with diencephalic damage, and more so with brainstem damage determined by reorganization. For example, an increase of EEG coherence in the combination of symmetrical temporal zones with damage to limbic structures reflecting an increase in interhippocampal interaction is also noted in damage to diencephalic (primarily thalamic) and stem structures. This similarity, on the one hand, underlines the intimate interactions of separate links of the regulatory systems and, on the other hand, reveals the presence of universal elements in the formation of whole adaptive brain reactions with damage to its regulatory structures.

One other distinctive feature of the reorganization of intercentral interactions in case of regulatory structure damage is the reciprocal nature of changes in the combinations of brain biopotentials (Boldyreva, 2000). This is relative to the specifics of disturbance of regional and frequency coherence characteristics, interactions of changes in intra- and interhemispheric connections of the primary physiological rhythm diapasons.

It is noteworthy that, in pathology of the regulatory sections of the brain, EEG often shows mainly not focal manifestations of pathological activity, but rather changes in the spatial organization of the dominating rhythms. In particular, with tumors of diencephalic localization, an increase in the synchronization of biopotentials of anterior portions of the brain is characteristic. This is expressed in the generalization of alpha rhythm or the shift of its focus to central-frontal areas, the intensification of theta activity which may acquire a generalized nature. Disturbance of regional EEG features in the form of the deletion of zonal differences in the involvement of diencephalic structures in the pathological process reflects the amplification of distant biopotential synchronization. This is also reflected in the changes of EEG spectral characteristics and, in particular, the average frequency power spectrum. Figure 3 shows that, with damage to hypothalamic structures along with a decrease (in comparison with normal values) in mean frequency most prominent in occipital and central regions, there is a marked evening out of regional differences of this parameter. This type of EEG reorganization is accompanied by a weakening of the reactive properties of the brain and a disturbance of the selectivity of reaction of separate cortical zones to stimuli of various modalities.

It is important to note that such a pattern of evening out of regional differences of brain electrical processes is noted in healthy subjects in transition to somnolence, thus underlining the functional importance of such an EEG pattern.

A particular form of spatial reorganization of alpha activity is noted in tumor damage to mediobasal regions of the temporal lobe with the involvement of the hippocampus and close-lying structures in the pathological process. In these cases, at early stages of tumor growth there is not a weakening, as in cortical lesions, but an increase in alpha activity in the zone of projection of the tumor in the temporal region of the affected hemisphere. The intensified activity is accentuated by afferent stimulation. The noted functional properties of the above-mentioned rhythm, its frequency characteristics, which may not coincide with the frequency of occipital alpha rhythm, and the localization of its

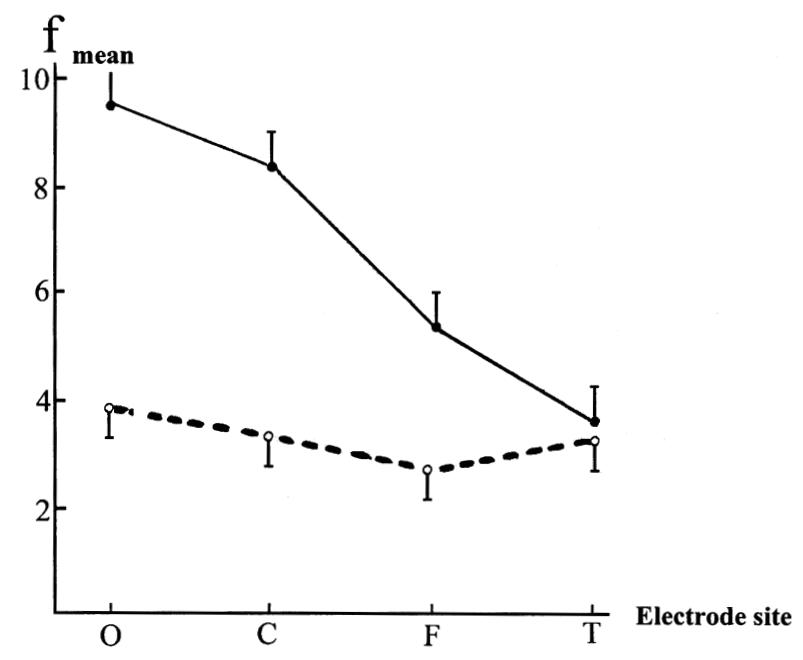

Figure 3. Regional features of EEG spectral characteristics in healthy subjects and patients with damage to diencephalic structures. $\mathrm{X}$-axis $=$ cortical region; $\mathrm{Y}$-axis $=$ mean EEG power frequency spectrum (f mean). Solid line $=$ normal $(n=50)$, dotted line $=$ pathology $(n=28)$. 
equivalent dipole sources, using the Brainloc method, has allowed the identification of the revealed EEG pattern as a reflection of the activation reaction of the hippocampus, involved in the pathological process. This concept is confirmed as a result of the investigation of the pattern of coherence spectrum (Figure 4). As evident, in regions corresponding to the tumor projection zone, on the background of a decrease in EEG coherence of most the frequency components, the alpha activity, in contrast to symmetrical regions of the intact hemisphere, is coherent. This reflects the formation of an atypical system of corticalhippocampal interaction. With afferent stimulation, the coherence of the so-called "hippocampal alpha rhythm" (Boldyreva, 2000) increases markedly.

The revealed features of the alpha activity topography in damage to limbic structures allow us to extend the customary concepts in clinical electroencephalography of the interpretation of EEG interhemispheric asymmetry in conditions of organic brain pathology.

One of the most complex problems faced in the study of integrative brain activity is the clarification of neurophysiological mechanisms of consciousness. Among various electrophysiological approaches to the research of this problem, of theoretical and practical significance, is the study of the features of EEG reorganization in patients with various forms of consciousness disturbance resulting from organic CNS disease. Whereas data of visual and spectral assessment of EEG and evoked potentials phenomena is greatly productive in the search for prognostic criteria of the development of pathological states with loss of consciousness (Danze, Brulem, \& Haddadm, 1989; Gnezditsky, Popova, \& Fedin, 1996; Ogura, 1992; Rath \& Klein, 1991), analysis of EEG intercentral interactions was found to be most productive for the study of systemic cerebral maintenance of various forms of disturbed consciousness (Dobronravova, 1990; Grindel, 1985; Sharova, 1999; Sharova, Kulikov, \& Zaitsev, 1997).

Over a long period of time, the structure of coherent EEG connections has been studied in our laboratory as the basis for research into the systemic organization of the human brain in conditions of coma and borderline postcomatose unconscious states (apallic syndrome or vegetative states, akinetic mutism, etc.) in patients with tumor and traumatic CNS damage.

With the aid of such an approach, it has been shown that one of the neurophysiological mechanisms of consciousness depression and the development of comatose states in patients with brain tumors is the destruction of intercentral connections of cerebral electrical processes with the decrease of mean levels of EEG coherence. Furthermore, electrographic heterogeneity of comatose states has been revealed, and specific changes in indices of interhemispheric asymmetry coherence for separate coma stages have been described. At a stage of deep coma, with domination in EEG of hypersynchronous theta rhythm of $5 \mathrm{~Hz}$ frequency reflecting the prevalence of the influence of diencephalic and limbic structures in the cortex, on a background of marked diffuse decrease in coherence, there is a predominance of connections in the theta diapason on the right. At the stage of terminal coma, with the presence of flashes of rhythmic bilateral monomorphic slow waves $(1.5-2 \mathrm{~Hz})$ on the EEG of brain stem nature, there is a marked global drop in EEG coherence with a relatively small increase in low frequencies in the left hemisphere. These data apparently reflect the stage-by-stage domination of separate regulatory cerebral structures (brainstem, diencephalic, limbic) on the background of cortical inhibition in these critical brain states.

\section{Coh}
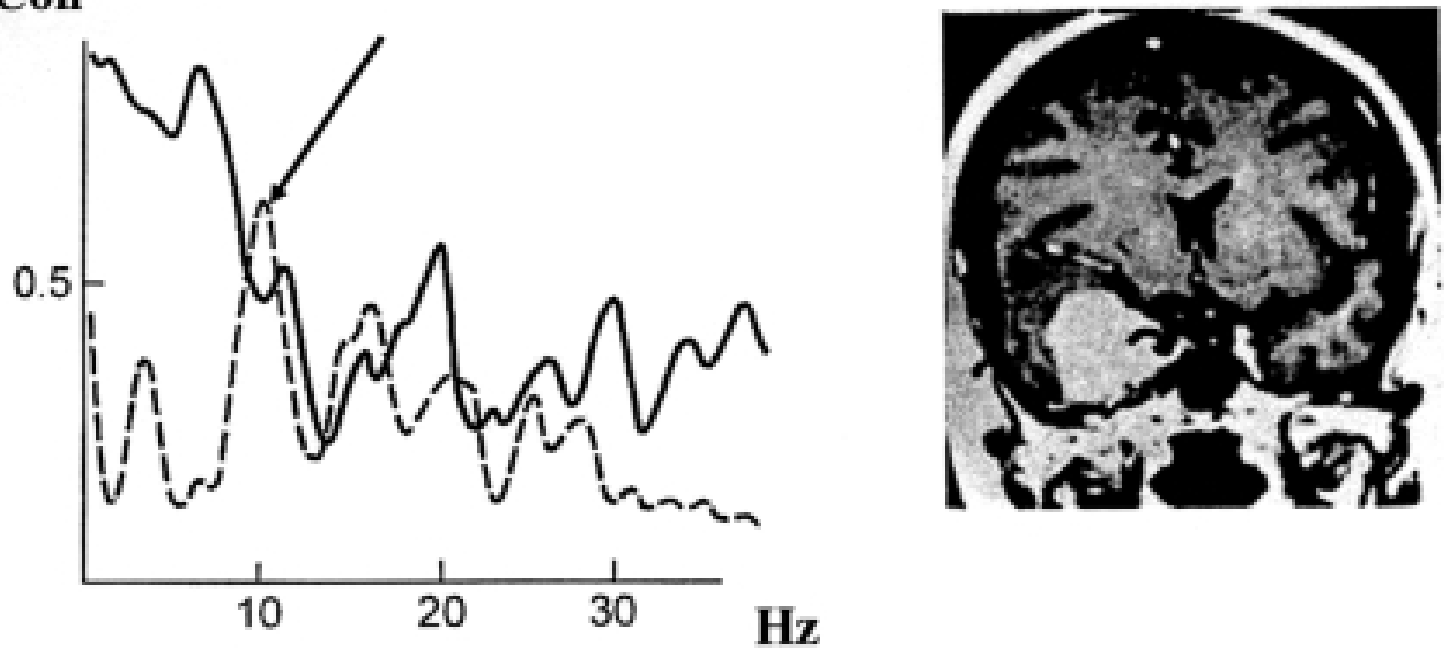

Figure 4. EEG spectrum coherence at temporal-frontal regions within the right and left hemispheres of patient C. with a tumour in the mediobasal regions of the left fronto-temporal lobe.

Solid line $=$ intact, dotted line $=$ damaged hemisphere. $\mathrm{X}$-axis $=$ frequency $\mathrm{Hz}$, Y-axis $=$ coherence. Arrow shows an alpha peak in the EEG at tumour projection zone. On the right is the computerised brain tomogram. 


\section{Studies in Patients with Disorders of Consciousness}

The study of the dynamics of intercentral interactions in the process of the recovery of consciousness (from coma to clear consciousness) carried out on the parameters of mean levels of EEG coherence in patients with severe craniocerebral trauma has lead to the revelation of several common mechanisms of this process, as displayed in Figure 5. First of all, it is obvious that changes in coherence during recovery is not gradual and smooth, but of a discrete and phasic nature, manifesting in marked changes (decrease, increase) of connections in the transition from one stage of recovery to another. Furthermore, a correlation of the changes in EEG coherence and mental activity has been revealed: Each stage of recovery corresponds to specific reorganization of intercentral interaction. It has been shown that the extension of functional capability at each stage of mental recovery can be based on either the disinhibition and fortification of old connections, or the formation of new, often atypical for previous stages, connections. The latter variant is particularly typical for early stages of recovery of consciousness (transition from coma to vegetative state and then to akinetic mutism).
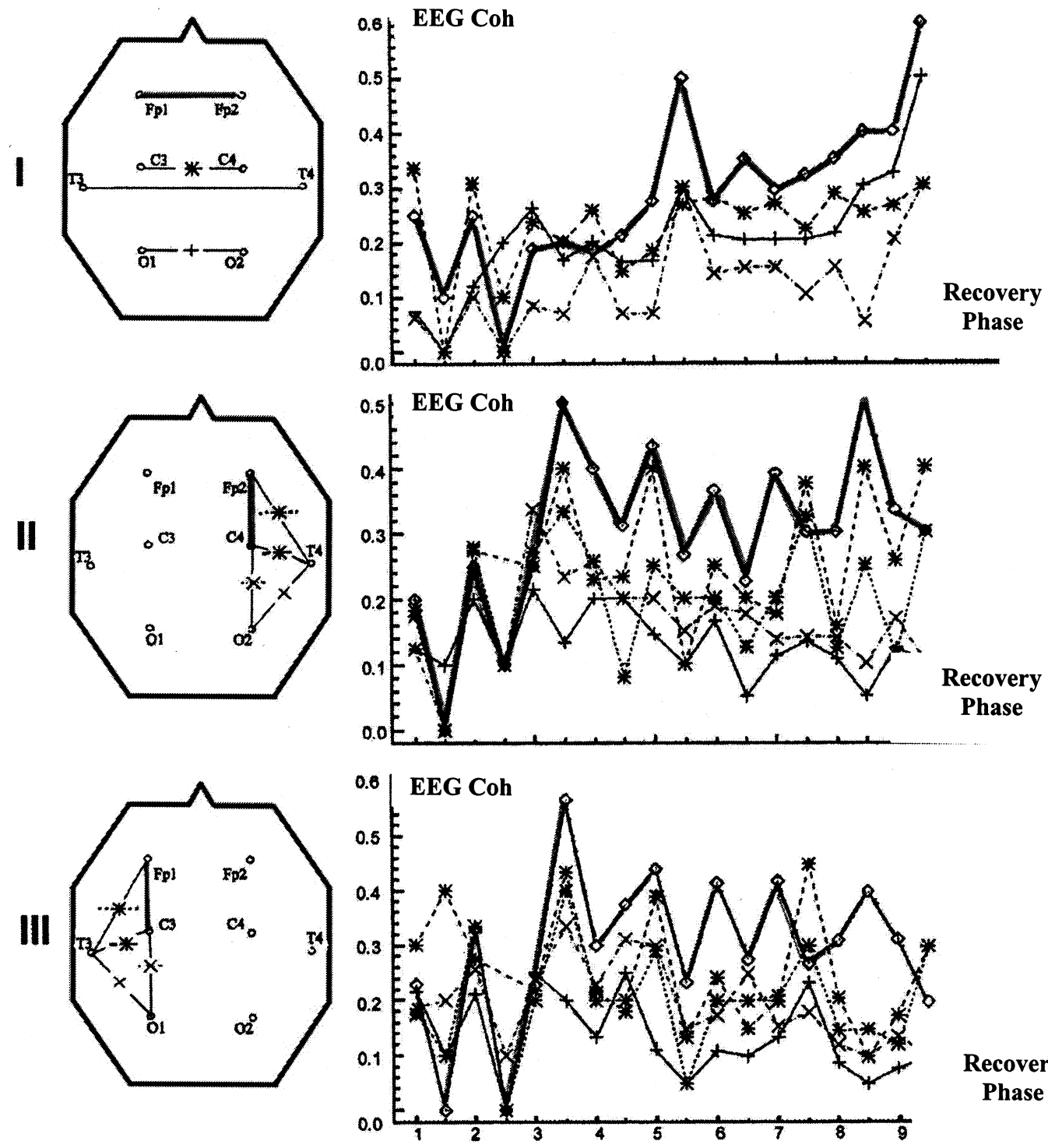

\section{Recovery \\ Phase}

Figure 5. Changes in interhemisphere $(\mathrm{A})$ and intrahemisphere ( $\mathrm{B}=$ right, $\mathrm{C}=$ left) EEG coherence at various stages of recovery of mental activity in a patient with sever cranio-cerebral trauma.

$\mathrm{X}$-axis $=$ mental recovery stage, assessed according to the scale of Dobrokhotova,, Zhavoronkova, Bragina, Gogitidze \& Zayzev (1993): $1=$ coma, $2=$ apallic syndrome, $3=$ akinetic mutism, $4=$ akinetic mutism with emotional reactions, $5=$ mutism with speech comprehension, $6=$ speech disintegration, $7=$ Korsakoff's syndrome, $8=$ Intellectual-mnestic impairment, $9=$ psychopathy-like syndrome.

Y-axis $=$ values of mean EEG coherence levels, averaged for observation group $(n=55)$.

On the left of the figure is presented a schematic demonstration of the analyzed electrode pair, with coherence values on the right of the figure. 
Observation of patients with positive dynamics of mental activity during compensation revealed a domination of EEG coherence at anterior hemisphere regions - interhemispheric frontal and intrahemispheric fronto-central connections, which is an uncharacteristic feature for patients with chronic vegetative states. Such a direction of changes in intercentral interactions probably reflects the transition to a "frontal regulation type," typical for healthy subjects, as an essential condition for successful recovery of consciousness (Sharova, 1999).

It is important to note the presence of several differences in central neurodynamics related to lateralization in predominantly traumatic brain damage. In left hemisphere damage, the reorganization of EEG coherence is discrete (probably reflecting greater energy requiring compensation mechanisms) whereas right hemisphere reorganization is smoother. These data are evidence of particular differences in the mechanisms of recovery in traumatic patients with various areas of damage (Sharova, 1999) and of the necessity to consider this factor in the development of rehabilitation strategy.

\section{Discussion}

The study of spatial-temporal EEG organization in healthy subjects in various functional states and in patients with cerebral pathology using coherence analysis has provided supportive data for the interpretation of the neurophysiological mechanisms of the formation of various CNS states. It is important to note that the analysis of coherence structure, reflecting the extent of synchronization of electrical activity in various brain regions, has led to research into the features of brain functioning as an integral system. At the same time, consideration of regional properties of EEG coherence and its specifics for separate physiological rhythm bands allows the clarification of the nature of involvement of intracortical and cortico-subcortical interactions.

EEG coherence analysis in healthy subjects has led to the revelation of a series of common traits of spatial-temporal organization of brain electric processes and, using substantial statistical material, according to parameters of mean coherence level, has provided quantitative values of inter- and intrahemispheric interactions, which are used as normative data. Along with common traits of EEG organization in healthy subjects, regional frequency coherence characteristics have been revealed, determined by individual asymmetry profiles, which are evidence of the non-identical mechanisms of the formation of EEG patterns in right- and left-handed subjects. Among these differences is the predominance in right-handed subjects of the reciprocal nature of coherence changes during changes in functional state and the synphasic nature of reorganization of coherence parameters in left-handed subjects. Most probably, it is for this reason that, in the rehabilitation of right-handed patients with the sequences of craniocerebral trauma, the activation of one of the hemispheres is often accompanied by the decrease of the functional capability of the other hemisphere, leading to a protraction of the recovery process in comparison to left-handed patients (Dobrokhotova, Zhavoronkova, Bragina, Gogitidze, \& Zayzev, 1993) Along with this, in diffuse brain damage (result of ionizing radiation), in comparison to right-handed patients, left-handed patients have more prominent development of epileptiform synchronization, accompanied by more severe epileptic attacks (Zhavoronkova, Ryzhov, Barmakova, \& Kholodova, 2002).

It has been established that a required condition for the functioning of the healthy brain is the presence of an optimal level of interhemispheric EEG coherence asymmetry, manifesting in the predominance of the combination of biopotentials in the dominant hemisphere. Confirmation of the fact that this property can be a vital indication of brain activity is the smoothing of interhemispheric asymmetry in states of decreased vigilance - somnolence in healthy subjects and the fact that in patients with diffuse post-radiation brain damage, the extent of the decrease in optimal interhemispheric asymmetry level correlates with the level of cognitive deficit (Zhavoronkova, 2006; Zhavoronkova, Kholodova, Zubovsky, Gogitidze, \& Koptelov, 1995; Zhavoronkova, Ryzhov, Barmakova, \& Kholodova, 2002).

The result of the study of a wide range of CNS states, including various forms of cerebral pathology, has allowed us to expand the scope of the concept of the reflection of EEG coherence interaction characteristics in various structures, to formulate the concept of various structural determinants of inter- and intrahemispheric coherence. According to this concept, the structure of inter-hemispheric connections predominantly reflects the state of median structures, intrahemispheric lateral, short connections-intracortical interactions and intra-hemispheric median, long connectionscortico-subcortical interactions within each hemisphere.

This concept, along with the revealed properties of the manifestation of inter-hemispheric asymmetry of spatialtemporal EEG organization, has provided the basis for the interpretation of neurophysiological mechanisms of the formation of various brain functional states.

In models on increasing depression of consciousness or recovery of cerebral activity, it has been shown that the reorganization of intercentral interactions, including interhemispheric EEG asymmetry, is dynamic in nature and is determined not only by hemispheric specificity of cortical elements, but also by the state of median regulatory brainstem-diencephalic structures. Furthermore, of importance in the interpretation of the mechanisms of interhemispheric asymmetry formation is the concept developed on the basis of clinical data of intimate functional connections of diencephalic structures with the right hemisphere and brainstem structures with the left hemisphere. Based on this data, confirmed by our EEG studies of the dynamic nature of interhemispheric asymmetry, EEG coherence during the development of pathological states can be considered 
as a reflection of the shifts in activity dominance of separate regulatory brain structures in the process of disturbance of the integrity of brain activity.

Data of the features of certain structural types of EEG coherence and the contribution of separate regulatory brain structures (diencephalic, brainstem, limbic) to spatial-temporal EEG organization has formed the basis for the interpretation of neurophysiological mechanisms of various forms of consciousness disturbance (coma and post-coma states) in patients with organic brain damage. As discovered, during the process of post-comatose mental recovery with the dynamic nature of reorganization of intercentral interactions, there is a reflection of the properties of the brain functional systems providing each stage of recovery. Neurophysiological analysis of the stages of recovery of consciousness is one of the principal directions of our current studies.

Part of the prospective directions in the study of the formation of systemic brain reorganization is the study of morpho-functional determinacy of various forms of brain electrical activity. Such an approach can be carried out through the analysis of the localization of equivalent dipole sources of the most informative EEG patterns and the development of program superposition of these data with the results of brain magnetic resonance tomography. Our initial experience in the noted directions has led to the determination of the non-indentical correspondence of dipole sources of various pathological EEG patterns and morphological changes in brain matter (Boldyreva et al., 2005). Furthermore, the registration of pathological EEG forms outside the zone of destruction reflects the possibility of the localization of lesions invisible to MRI using dipole localization of concomitant lesions. These lesions of pathological EEG pattern generation not accompanied by structural changes (according to $\mathrm{CT}$ and MRI) or severe corresponding focal neurological symptoms can markedly alter the nature of the interaction of separate brain regions and determine the development of new altered intercentral interactions. The latter, in turn, correlates with changes in the integration of brain activity and accentuates not only the topical, but also the functional significance of the method of electroencephalography.

\section{References}

Barchas, P.K.,\& Perlaki, K.M. (1986). Processing of preconsciously acquired information measured by hemispheric asymmetry and selection accuracy. Behavioral Neuroscience, 10, 343-351.

Beaumont, J.G., Mayes, A.R., \& Rugg, M.D. (1978). Asymmetry in EEG coherence and power: Effect of task and sex. EEG and Clinical Neurophysiology, 45, 393-402.

Boldyreva, G.N. (1994). Stabil'noct' spektral'no-kogerentnyh haracteristik EEG cheloveka [Stability of EEG spectralcoherence characteristics in human] Uspekhi fiziologicheskih nauk, 25, 68.
Boldyreva, G.N. (2000). Electrical aktivnost' mozga cheloveka pri porajenii diencefal'nih I limbicheskih structur [Electrical activity of human brain in lesions of the diencephalic and limbic structures]. Moskow: Nauka.

Boldyreva, G.N., Sharova, E.V., \& Dobronravova, I.S. (2000). Rol' regulatornich structur $\mathrm{v}$ formirovanii EEG cheloveka [The role of cerebral regulatory structures in the formation of human EEG]. Fiziologija cheloveka, 26, 19-34.

Boldyreva, G.N., Sharova, E.V., Koptelov, Yu. M., Shchepetkov, A.N., Nikitin, K.V., Kornienko, V.N., \& Fadeeva, L.M. (2005). Issledovanie geneza patologicheskich patternov EEG pri opusholevom I travmaticheskom poragenii mozga cheloveka [Study of genesis of pathological EEG patterns in tumor and traumatic lesions of the human brain]. Fiziologija cheloveka 31, 24-32.

Boldyreva, G.N., Sharova, E.V., Zhavoronkova, L.A., \& Dobrokhotova, T.A. (1992). Otrazhenie raznyh urovney reguljacii mozgovoy dejatel'nosty cheloveka v spektral'nokogerentnyh parametrah [The reflection of different levels of regulation the human brain activity at the spectral-coherence parameters]. Zhurnal visshey nervnoy dejatelnosty, 42, 439449.

Boldyreva, G.N., \& Zhavoronkova, L.A. (1989). Kharakteristika mezhpolusharnih vzaimootnoshenii v ocenke funkcional'nogo sostojania mozga cheloveka [Characteristic of EEG interhemispheric interaction at the estimation of the brain functional state]. Zhurnal visshey nervnoy dejatelnosty, 39, 215-220.

Boldyreva, G.N., Zhavoronkova, L.A., Sharova, E.V., \& Dobronravova, I.S. (2003). Mezhcenral'nye otnoshenija EEG kak otrazhenye systemnoy organizacii organizacii $\mathrm{v}$ norme $\mathrm{i}$ patologii [The intercentral interaction of EEG as reflection of system organization of the human brain in normal and pathology]. Zhurnal visshey nervnoy dejatelnosty, 53, 391401.

Bragina, N.N., \& Dobrokhotova, T.A. (1981). Funkcional'nie asimmetrii cheloveka [Functional asymmetries of human]. Moskow: Medicine.

Danze, F., Brulem J.F., \& Haddadm, K. (1989). Chronic vegetative state after severe head injury. Neurosurgical Review, 12, 477499.

Dobronravova, I.S. (1990). Reorganizacij electricheskoy aktivnosti mozga sheloveka pri ugnetenii soznaniy (komatoznii sostojniy) [Reorganization of electrical activity of the human brain under depression of consciousness (comatose conditions)]. Zhurnal visshey nervnoy dejatelnosty, 40, 1105-1114.

Dobrokhotova, T.A., \& Bragina, N.N. (1977). Funkcional'nay asimmetriy I psichizheskay patologiy ozhagovich porajeniy mozga [Functional asymmetry and mental pathology of brain local pathology] Moskow: Medicine.

Dobrokhotova, T.A., Zhavoronkova L.A., Bragina, N.N., Gogitidze, N.V., \& Zayzev, O.S. (1993). Vosstanovlenye soznanija posle dlitel'noy komy y parvshey I levshey s tyazheloy cherepnomozgovoy trvmoy (kliniko-electroencefalograficheskoye issledovaniye [The restoration of consciousness of right-handers 
and left-handers with severe cranio-cerebral trauma (clinicelectroencephalographic investigation)]. Social'naya I klinicheskaya psykhiatriya, 1, 23-28.

Farber, D.A. (1990). Principi sistemnoi strukturno-funkcional'noi organizacii mozga, osnovnie etapi ego formirovaniya [Principles of the system structurally-functional organization of the brain, the basic stages of its formation]. In Strukturno-funkcional'naya organizacia razvivaushegosia mozga (pp.168-179). Leningrad: Nauka.

Gevins, A.S., \& Remond, A. (Eds). (1987). Methods of analysis of brain electrical and magnetic signals. In Handbook of EEG and Clinical Neurophysiology. Revised series. (Vol. 1, 40-52). Amsterdam: Elsevier.

Gnezditsky, V.V., Popova, L.M., \& Fedin P.A. (1996). Prognosticheskoe znachenie neurofisiologicheskih pokazatelei pri netravmaticheskom appalicheskom syndrome [Prognostic significance of neurophysiological index at untraumatic apallic syndrome]. Anestesia and reanimatology, 2, 16-21.

Grindel, O.M.. (1985). Mezhcentral'nye otnoshenija v kore bol'shogo mozga po pokazatelum kogerentnosti EEG pri vosstanovlenii soznaniy I rechy posle dlitel'noy komy [The intercentral interaction in cortex brain on index of EEG coherence at recovery of consciousness and speech after long coma]. Zhurnal visshey nervnoy dejatelnosty, 35, 6067.

Livanov, M.N. (1972). Prostranstvennay organizaciy processov golovnogo mozga [Spatial organization of brain processes] Moskow: Nauka.

Lopez da Silva, F.H. (1991). Neural mechanisms underlying brain waves: From neural membrance to networks. EEG and Clinical Neurophysiology, 79, 81- 93.

Newton, T.F., Leuchter, A.F., Walter, D.O., Van Gorp, W., Stern, C., Mandelkern, M., \& Weiner, H. (1993). EEG coherence in men with AIDS: Association with subcortical metabolic activity. Journal of Neuropsychiatry and Clinical Neuroscience, 5, 316329.

Ogura, M. (1992). Neurophysiological findings and the prognosis of early-stage vegetative state. In K. Takakura \& T. Kanno (Eds.), Proceedings of the $1^{\text {st }}$ annual meeting of the Society for Treatment of Coma, Kyoto, 1, 21-28.

Rappelsberger, P., \& Petshe, H. (1988). Probability mapping: Power and coherence analysis of cognitive processes. Brain Topography, 1, 45-51.

Rath, S.A., \& Klein, H.J. (1991). Current applications of the EEG in the comatose neurosurgical patient. American Journal of EEG Technology, 31, 65-81.

Rusinov, V.S. (1969). Dominanta: elektrofiziologizheskie issledovaniy [Dominanta: Electrophysiological research]. Moscow: Medicine.

Rusinov, V.S., Grindel, O.M.. Boldyreva, G.N., \& Vakar E.M. (1987). Biopotencialy mozga cheloveka [Human brain biopotentials]. Moskow: Medicine.

Schack, B., \& Krause, W. (1995). Dynamic power and coherence analysis in ultra short-term cognitive processes. Brain Topography, 8, 127-136.
Sharova, E.V. (1999). Adaptivno-kompensatornie perestroiki bioelektricheskoi aktivnosti mozga cheloveka pri povregdenii stvolovih obrazovanii [The adaptive-compensatory reorganizations of the human brain's bioelectric activity at the brainstem damage]. Summary of doctoral dissertation. Moskow: Institute of Higher Nervous Activity and Neurophysiology RAS.

Sharova, E.V., Borodkin, S.M., Gognitidze, N.V., Lukianov, V.I., \& Muhanov, T.K. (1992). Funkcional'naya znachimost harakteristik prostranstvenno-vremennoi organozacii EEG u bol'nih s cherepno-mozgovoi travmoi [The functional importance of spatial-temporal EEG-organization's characteristics in patients with heavy traumatic brain injury ]. Fiziologija cheloveka, 18, 22-30.

Sharova, E.V., Manelis, N.G., Kulikov, M.A., \& Barkalaia, D.B. (1995). Vliyanie stvolovih struktur na formirovanie funkcional'nogo sostoyania bol'shih polushari golovnogo mozga [Influence of brainstem structures on the functional state of human brain hemispheres]. Zhurnal visshey nervnoy dejatelnosty, 45, 876-885.

Sharova, E.V., Kulikov, M.A., \& Zaitsev, O.S. (1997). The peculiarities of EEG dynamics during mental recovery after long-term posttraumatic coma. EEG and Clinical Neurophysiology, 103, 207.

Sharova, E.V., Obraztsova, E.R., Zaitsev, S., Kulikov, M.A., \& Urakov, S.V. (2001). Osobennosti EEG pri posttravmaticheskom korsakovskom sindrome [EEG peculiarities in posttraumatic Korsakov's syndrome]. Zhurnal Nevrologii i psihiatrii im. S.S.Korsakova, 101, 32-38.

Shepoval'nikov, A.N., \& Citseroshin, M.N. (1999). Evolucionnie aspekti stanovlenia integrativnoi deyatelnosti mozga cheloveka [Evolutionary aspects of the integrative human brain activity becoming] Rossiiskiy fisiol. Jurnal imeni I.M.Sechenova, 85, 1187-1207.

Thatcher R.W. (1994). Cyclic cortical reorganization, origins of human cognitive development. In G. Dawson \& K. Fisher (Eds.), Human behavior and the developing brain (pp. 232266). New York: Guilford Press.

Tucker, D. N., Roth, R.S., \& Bair T.B. (1986). Functional connections among cortical regions: Topography of EEG coherence. EEG and Clinical Neurophysiology, 63, 242-250.

Zhavoronkova, L.A. (2006). Pravshi-levshi: mezhpolusharnaja asimmetrja elektricheskoi aktivnosti mozga cheloveka [Righthanders - left-handers: interhemispheric asymmetry of electrical activity of the human brain] Moscow: Nauka

Zhavoronkova, L.A., Boldyreva, G.N., \& Dobrokhotova, T.A. (1988). Zavisimost' organizacii elektricheskoy aktivnosti mozga cheloveka ot dominantnosi polusharija [The dependence of electrical activity organization of the human brain on hemispheric dominance]. Zhurnal visshey nervnoy dejatelnosty, 38, 620-626.

Zhavoronkova, L.A., Kholodova, N.B., Zubovsky, G.A., Gogitidze, N.V., \& Koptelov, Y.M. (1995). EEG power mapping, dipole source and coherence analysis in Chernobyl patients. Brain Topography, 8, 161-168.

Zhavoronkova, L.A., Ryzhov, B.N., Barmakova, A.B., \& Kholodova, N.B. (2002). Osobennosti narushenja EEG I 
kognitivnikh funkcii posle vozdeistvija radiacii [Features of EEG and cognitive disorders after exposure to radiation]. Doklady Rossiiskoy akademii nauk, 386, 418-422.

Zhavoronkova, L.A., \& Trofimova, E.V. (1997). Dinamika kogerentnosty EEG I dvigatel'nikh reakciy u pravshey i levshey pri zasipanii. Soobscheniye I. Analiz bnutripolusharnykh sootnosheniy [The dynamics of EEG coherence and movement reactions in right-handers and left-handers during sleeping. Communication I. Analysis of intrahemispheric interaction]. Fiziologija cheloveka, 23, 18-26.
Zhavoronkova, L.A., \& Trofimova, E.V. (1998). Dinamika kogerentnosty EEG u pravshey i levshey pri zasipanii. Soobscheniye II. Analiz mezhpolusharnykh sootnosheniy [The dynamics of EEG coherence in right-handers and left-handers during sleeping. Communication II. Analysis of iterhemispheric interaction]. Fiziologija cheloveka, 24, 32-40.

Received April, 17, 2006

Revision received September, 22, 2006 Accepted January, 17, 2007 